\title{
High-Performance Vector Control without AC Phase Current Sensors for Induction Motor Drives: Simulation and Real-Time Implementation
}

\author{
Younes Azzoug ${ }^{\mathrm{a}, \mathrm{b}, *}$, Mohamed Sahraoui ${ }^{\mathrm{a}, \mathrm{c}}$, Remus Pusca ${ }^{\mathrm{b}}$, Tarek Ameid ${ }^{\mathrm{b}}$, Raphaël Romary ${ }^{\mathrm{b}}$, \\ Antonio J. Marques Cardoso ${ }^{c}$ \\ ${ }^{a}$ Electrical Engineering Laboratory of Biskra (LGEB), University of Biskra, Algeria. \\ ${ }^{\mathrm{b}}$ Univ. Artois, UR 4025 LSEE F-62400, Bethune, France. \\ ${ }^{\mathrm{c}}$ CISE - Electromechatronic Systems Research Centre, University of Beira Interior, Covilhã, Portugal.
}




\title{
High-Performance Vector Control without AC Phase Current Sensors for Induction Motor Drives: Simulation and Real-Time Implementation
}

\begin{abstract}
The main purpose of this paper is to develop a high-level performance, and low-cost current sensorless control strategy for Induction Motor (IM) drives. Therefore, a new phase-current regeneration method, for current sensorless vector control in induction motor drives is introduced. The idea is based on the reconfiguration of the Luenberger adaptive observer for currents estimation, using the information provided by the dc-link voltage sensor. The basis of the proposed control and the theoretical study of the modified adaptive observer are presented. Several simulation and experimental tests were performed on an induction motor of $1.1 \mathrm{~kW}$ working under different operating conditions. The obtained results prove and testify the relevance, workability, and practicability of the suggested currents sensorless vector control strategy.
\end{abstract}

Keywords: Vector control; sensorless control; induction motor; currents estimation; fault-tolerant control.

\section{Introduction}

Vector control of induction motors, initiated by Blaschke in 1972, is broadly used in different applications for variable speed drives, mainly due to its independent control structure. Vector control method allows the decoupling between both flux and torque, to get an independent control like in the case of DC machines [1]. This control strategy becomes nowadays more and more attractive. Indeed, many researchers have been showing interest in this technique due to its simplicity and ability to control different AC machine drives, such as permanent magnet synchronous machines [2], permanent magnet brushless machines [3,4], variable reluctance motors [5], and induction motors [6,7]. The induction machine is still the workhorse in industry, due to its wellknown advantages, such as the simplicity of construction, low acquisition and maintenance costs, robustness, high performance, remarkable reliability and its adaptability to harsh environments [8-10].

A vector controlled induction motor requires a feedback loop of two phase's stator currents and speed, at least, to get a perfect decoupling between flux and torque, and thus a high-performance variable speed drive. In these control systems, current sensors are, generally, the components most prone to failures [11] due to connection problems, noise, offset, or drop in voltage level of the battery. All these failures lead to an overcurrent in the system, and torque ripple, causing dysfunctions in the control string. Indeed, in the industry, reduction of control system costs is one of the main challenges.

To minimize the problems caused by speed sensor failures, one obvious way is to reduce their number in the control system; however, the control must be capable to maintain the same accuracy as before. In this context, sensorless methods have been the subject of a particular research. During the twentieth century, speed sensorless techniques have become more sophisticated, efficient, effective, and have achieved good results. [12-15]. In recent years, research on power electronics and signal processors has grown rapidly; for this reason, current sensing techniques with a reduced number of sensors has attracted much attention from the research community, in order to avoid faults caused by current sensors, improve the sensor fault tolerance of the system, enhance the reliability, reduce the costs of industrial applications, decrease the complexity of the systems, simplify the implementation, and minimize the volume of the systems as much as possible. Due to these merits, several publications have appeared in recent years documenting current sensorless control of variable speed drives and Voltage Source Inverters (VSIs). Among them, a speed control technique with a single dc-link current sensor for a Permanent Magnet Synchronous Motor (PMSM) used to drive the air-conditioning compressor of an electric vehicle is proposed in [16]. However, this method cannot be achieved with a standard Pulse Width Modulation (PWM), due to the fact of the active voltage shorter duration time, which needs an adjusted PWM. This method is used also for permanent magnet AC servo systems associated with a sliding mode observer for rotor position estimation [17]. In [18, 19] a high-frequency injection technique applied for low-speed sensorless control of interior permanent magnet synchronous machines with a single dc-link current sensor is proposed, based on a six-direction square wave high-frequency injection method to extend the voltage vector to the measurable region to achieve the three-phase current reconstruction without modifying the space vectors of the PWM. Another single current sensor method for PMSM three-phase current reconstruction is described in [20, 21]. This method can be realized with a current sensor and a shunt resistor in the dc-link of the VSI. In [22] a model predictive torque control VSI fed IM drive without current sensors is presented. The drawback of this method is that the switching frequency is variable, which conducted the authors to add an algorithm for stabilization. Reference [23] proposes a stator frequency and power control method of a doubly-fed induction generator without stator voltages and current sensors; only the rotor currents are necessary for the control. In [11, 24], the authors 
propose a direct predictive control without current sensors for induction motor and permanent magnet synchronous motors, and where the future values of the stator currents are estimated by a prediction-correction algorithm. The results obtained in those papers suggest that at rated load condition, the performance is worse than that under a no-load condition. Another solution is described in [25], where the authors give a method to reconstruct the stator currents by using three fuzzy logic controllers with different inputs for degraded operation mode. To get information about the three line currents, the authors in $[26,27]$ propose a technique using a single current sensor at the dc-link, and some modifications in the modulation algorithm, in order to guarantee the reliability of the measurements with degraded performance operating conditions. An algorithm for reconstructing the phase currents of the induction machine under Direct Torque Control (DTC) is presented in [28, 29]. It was shown that the information can be obtained from an additional shunt resistor and a current sensor at the dc-link of the inverter. Some other methods are based on observers. An extended Kalman filter is used in [30, 31] to estimate the stator currents of a wound rotor synchronous machine and PMSM, based on the motor parameters. As known, for high-performance experimental implementation, Kalman filter needs large sampling time. A method based on an adaptive observer is proposed in [32-34]. Here, the information required for reconstructing the phase currents is extracted from two sensors at the dc-link, one to measure the current and the other to measure the voltage. Other techniques adapt the PWM signal to ensure that the two-phase currents can be sampled in each control period [35-37].

The literature on Fault-Tolerant Control (FTC) against current sensor failures shows a variety of approaches for stator currents regeneration. In [38], a FTC technique against current sensors failure in IM drives is proposed, where the estimation of the stator currents is carried out by three adaptive observers with different inputs. Another FTC technique for current sensors faults in permanent magnet synchronous motor drives is described in [39], in which the stator currents are recovered using two adaptive observers. A current sensor FTC for wind energy conversion system with doubly-fed induction generator is proposed in [40]; this technique uses a predictive model to reconstruct the stator currents. A stator current sensors Fault Detection and Isolation (FDI) for vector controlled IM drives is investigated in [41], where the stator currents are calculated by algebraic relations. Two observers, based on the theory of Luenberger state observers, are developed in [42] and [43] to estimate the stator and rotor currents in the FTC of doubly-fed induction generators. The stator current observer uses the rotor current measurement as feedback and the rotor current observer uses the stator current feedback, which leads to a mutual dependence. Recently, several research papers [44-47] have proposed other techniques to estimate the stator currents, which are based on axes transformations and the healthy currents in FTC induction motor drives.

The present work is essentially focused on the implementation of an IM vector control without any current sensor feedback. The present paper includes several important features that are distinct from other already proposed approaches:

- Unlike methods that employ more than one observer, the proposed idea uses only one estimator in order to reconstruct the three line currents.

- The estimation is based on existing sensors in the control-loop, which are the dc-link voltage sensor and the incremental encoder, making this proposed approach distinct from the other solutions, which suggest for example an additional sensor in the dc-link for current measurement or a shunt resistor.

- In the literature of current sensors fault-tolerant control, most proposed methods for currents reconstruction are based on two observers at least, or one observer and the healthy sensors, which is not suitable to achieve an efficient fault-tolerant control in case of a failure in two or three sensors, but using the proposed method; a fault-tolerant control can be achieved even without current sensors.

- Simulation and experimental results show that the proposed algorithm for currents estimation achieves a high-performance sensorless control, under different conditions, namely at low-speed, during a speed reverse test, at variable speed, also with the rated load even with low-speed, as well as at a high-speed test. All these tests prove that the proposed method provides a high-level performance operation, contrary to the ones mentioned in the literature, which operate with degraded performance.

This study is intended to introduce a fundamental method to estimate the three stator currents. The adopted stator currents estimator scheme is simple, original, and it can be used in any IM drives control system.

This paper is organized into 6 sections. Section 2 briefly describes the used induction motor model, and the basics of the vector control. Section 3 analyses the theory and the design of the proposed current sensorless vector control. Simulation results are presented in section 4. Afterwards, section 5 discusses the experimental results. Finally, section 6 presents the main conclusions of the paper.

\section{Basic indirect rotor field oriented control} 2.1. Induction motor model 
Among the various models used to represent the induction motor, the one that will be used in this paper uses a reference frame $(d, q)$ linked to the rotating field, and takes the stator currents, the rotor fluxes, and the rotational speed as state variables. This model is expressed by the following system of equations, using the voltages as control variables:

$\frac{d}{d t} I_{s d}=-\lambda I_{s d}+\omega_{s} I_{s q}+\frac{k_{s}}{T_{r}} \varphi_{r d}+k_{s} \omega_{r} \varphi_{r q}+\frac{1}{\sigma L_{s}} V_{s d}$

$\frac{d}{d t} I_{s q}=-\omega_{s} I_{s d}-\lambda I_{s q}-\omega_{r} k_{s} \varphi_{r d}+\frac{k_{s}}{T_{r}} \varphi_{r q}+\frac{1}{\sigma L_{s}} V_{s q}$

$\frac{d}{d t} \varphi_{r d}=\frac{M}{T_{r}} I_{s d}-\frac{1}{T_{r}} \varphi_{r d}+\left(\omega_{s}-\omega_{r}\right) \varphi_{r q}$

$\frac{d}{d t} \varphi_{r q}=\frac{M}{T_{r}} I_{s q}-\left(\omega_{s}-\omega_{r}\right) \varphi_{r d}-\frac{1}{T_{r}} \varphi_{r q}$

$T_{e}=p \frac{M}{L_{r}}\left(\varphi_{r d} I_{s q}-\varphi_{r q} I_{s d}\right)$

$\frac{d}{d t} \Omega_{r}=\frac{1}{J}\left(T_{e}-T_{l}\right)-\frac{F}{J} \Omega_{r}$

where:

$\lambda=\frac{R_{s}}{\sigma L_{s}}+\frac{R_{r} M^{2}}{\sigma L_{s} L_{r}^{2}} ; \quad k_{s}=\frac{M}{\sigma L_{s} L_{r}} ; \quad T_{r}=\frac{L_{r}}{R_{r}} ; \quad T_{s}=\frac{L_{s}}{R_{s}} ; \quad \sigma=1-\frac{M^{2}}{L_{s} L_{r}}$

\subsection{Vector control}

The Indirect Rotor Field Oriented Control (IRFOC) of induction motors has as an objective to make the control of flux and torque similar to the one of the separately excited DC motor, where these parameters are controlled independently. In this case, the oriented rotor flux implies the following conditions:

$\varphi_{r d}=\varphi_{r} \quad$ and $\quad \varphi_{r q}=0$

From Eq. (3), Eq. (5), and Eq. (7), the flux and the torque expressions become:

$\varphi_{r}=\frac{M}{T_{s} s+1} I_{s d}$

$T_{e}=p \frac{M}{L_{r}} \varphi_{r} I_{s q}$

The electromagnetic torque depends only on just one single current, which is the quadrature stator current $I_{s q}$ (see Eq. (9)), and so the electromagnetic torque is similar to the one of DC machines, presented in the following equation:

$T_{e}=k^{\prime} \phi I$

Like in DC motors, two independent action variables $\left(I_{s d}, I_{s q}\right)$ are obtained, the first one for adjusting the flux, and the second one for adjusting the torque. From $E q .(4)$ it is obtained:

$\omega_{s}=\frac{M}{T_{r} \omega_{r}} I_{s q}+p \Omega_{r}$

From the integral of Eq. (11) it results the angle $\theta_{s}$ which will be used in all transformations.

$\theta_{s}=\int \omega_{s} d t$

The overall diagram of the indirect rotor field oriented control of an induction motor is illustrated in Fig. 1.

\section{Vector control without current sensors}

\subsection{Current sensorless vector control scheme}

The basic vector control scheme presented in Fig. 1 (where the symbol "*" denotes reference values) generally requires three current sensors, and in the best-case scenario, two current sensors. Instead, the recommended IRFOC scheme, described in this paper, uses only a single sensor for dc-link voltage 
measurement, as shown in Fig. 2. For this reason, a proper technique is proposed for reconstructing the stator currents and generating phase voltages, based on the modification of the basic voltage control scheme, and using a voltage vector synthesizer as well as a modified adaptive observer.

One of the most important objectives of the proposed current sensorless vector control is to overcome all defects caused by current sensors, as well as minimizing costs. This in turn allows simplifying the sampling circuit to just one sensor, responsible for the dc-link voltage measurement. The information provided by this voltage sensor will be used in the voltage synthesizer to generate the three-phase voltages applied to the machine.

\subsection{Stator currents estimation}

In order to design a high performance current estimator, and establish a good compromise between stability and simplicity of the observer, a model of the machine drive is defined in the reference frame linked to the coordinates $(\alpha, \beta)$ by the following state equations:

$\left\{\dot{X}=A\left(\omega_{r}\right) X+B U\right.$

where:

$X=\left[\begin{array}{llll}I_{s \alpha} & I_{s \beta} & \varphi_{r \alpha} & \varphi_{r \beta}\end{array}\right]^{T} ; \quad Y=\left[\begin{array}{ll}I_{s \alpha} & I_{s \beta}\end{array}\right]^{T} ; \quad U=\left[\begin{array}{ll}V_{s \alpha} & V_{s \beta}\end{array}\right]^{T}$

and:

$A=\left[\begin{array}{cccc}a_{1} & 0 & a_{2} & \omega_{r} a_{3} \\ 0 & a_{1} & -\omega_{r} a_{3} & a_{2} \\ a_{4} & 0 & a_{5} & -\omega_{r} \\ 0 & a_{4} & \omega_{r} & a_{5}\end{array}\right] ; \quad B=\left[\begin{array}{cc}1 & 0 \\ \sigma L_{s} & \frac{1}{\sigma L_{s}} \\ 0 & 0 \\ 0 & 0 \\ 0 & 0\end{array}\right] ; \quad C=\left[\begin{array}{cccc}1 & 0 & 0 & 0 \\ 0 & 1 & 0 & 0\end{array}\right]$

as well as:

$a_{1}=-\left(\frac{1}{T_{s} \sigma}+\frac{(1-\sigma)}{T_{r} \sigma}\right) ; \quad a_{2}=\frac{M}{\sigma L_{s} L_{r} T_{r}} ; \quad a_{3}=\frac{M}{\sigma L_{s} L_{r}} ; \quad a_{4}=\frac{M}{T_{r}} ; \quad a_{5}=\frac{1}{T_{r}}$

The general theory of an adaptive observer (see Eq.(14)) is based on the deterministic model of the system and on an adaptation mechanism for the estimated variable, through a gain matrix to ensure the system stability [34], [48]. Contrariwise, the proposed idea in this work is based on the conservation of the state model of the IM presented in $E q$. (13), with the gain matrix $K$ which has been determined by the classical pole placement procedure described in [49], and replacing the adaptive mechanism by the measured rotational speed, as well as feeding the observer by the stator voltages provided from the voltage synthesizer. This gives the stator currents estimation, as illustrated in Fig. 3.

The adaptive current observer is given by $E q$. (14) where the symbol "^" denotes estimated values:

$\left\{\begin{array}{l}\dot{\hat{X}}=A\left(\omega_{r}\right) \hat{X}+B U+K \xi \\ \hat{Y}=C \hat{X}\end{array}\right.$

where:

$\hat{X}=\left[\begin{array}{llll}\widehat{I_{s \alpha}} & \widehat{I_{s \beta}} & \widehat{\varphi_{r \alpha}} & \widehat{\varphi_{r \beta}}\end{array}\right]^{T} ; \quad \hat{Y}=\left[\begin{array}{lll}\widehat{I_{s \alpha}} & \widehat{I_{s \beta}}\end{array}\right]^{T} ; \quad \xi=\left[\begin{array}{ll}I_{s \alpha}-\widehat{I_{s \alpha}} & I_{s \beta}-\widehat{I_{s \beta}}\end{array}\right]^{T}$

Since there is no information about the measured currents, the vector $\xi$ becomes:

$\xi=\left[\begin{array}{ll}-\widehat{I_{s \alpha}} & -\widehat{I_{s \beta}}\end{array}\right]^{T}$

Considering the following system of equations, that present the current observer model in the complex format, the gain matrix $K$ is defined as follows:

$\left\{\begin{array}{l}\dot{\bar{X}}=\bar{A} \hat{X}+B \bar{V}_{s}+\bar{K} \xi \\ \hat{Y}=C \hat{\bar{X}}\end{array}\right.$

The determination of the gain matrix $K$ uses the conventional pole placement procedure, through the imposition of the observer's poles and consequently of its dynamics [50-53]. 
The characteristic equation of the observer is as follow:

$G(s)=\operatorname{det}(s I-(\bar{A}-\bar{K} C))$

Developing the different matrices $A, K$ and $C$ knowing that $\bar{K}=\left[\begin{array}{l}K^{\prime} \\ K^{\prime \prime}\end{array}\right]$ the following equation is obtained:

$$
\begin{gathered}
G(s)=s^{2}+\left(\frac{1}{\sigma T_{s}}+\frac{1}{\sigma T_{r}}-j \omega_{r}+K^{\prime}\right) s+\left(\frac{1}{T_{r}}-j \omega_{r}\right)\left\{\left(\frac{1}{\sigma T_{s}}+\frac{1}{\sigma T_{r}}\right)+K^{\prime}\right\} \\
+\left(\frac{M}{T_{r}}-K^{\prime \prime}\right)\left(\frac{M}{\sigma L_{s} L_{r}}\right)\left(\frac{1}{T_{r}}-j \omega_{r}\right)
\end{gathered}
$$

where $K^{\prime}$ and $K^{\prime \prime}$ are complex gains.

The dynamic equation of the observer is defined as:

$H(s)=s^{2}+l\left(\frac{1}{\sigma T_{s}}+\frac{1}{\sigma T_{r}}-j \omega_{r}\right) s+l^{2}\left(\frac{1}{T_{r}}-j \omega_{r}\right)\left\{\left(\frac{1}{\sigma T_{s}}+\frac{1}{\sigma T_{r}}\right)\right\}+\left(\frac{M}{T_{r}}\right)\left(\frac{M}{\sigma L_{s} L_{r}}\right)\left(\frac{1}{T_{r}}-j \omega_{r}\right)$

where $l$ is the proportionality constant, slightly bigger than the unit (see Table A.2, in the Appendix).

$E q$. (17) and Eq. (18) are in the form of the following equation:

$P(s)=s^{2}+2 \varepsilon \omega_{n} s+\omega_{n}^{2}$

The comparison of Eq. (17) and Eq. (18) gives for the expressions of $K^{\prime}$ and $K^{\prime \prime}$ :

$$
\left\{\begin{array}{l}
K^{\prime}=(l-1)\left(\frac{1}{\sigma T_{s}}+\frac{1}{\sigma T_{r}}-j \omega_{r}\right) \\
K^{\prime \prime}=(l-1)\left[\left\{\left[\frac{1}{\sigma T_{s}}+\frac{1}{\sigma T_{r}}\right] \frac{\sigma L_{s} M}{L_{r}}-\frac{M}{T_{r}}\right\}(l+1)-\frac{\sigma L_{s} M}{L_{r}}\left[\frac{1}{\sigma T_{s}}+\frac{1}{\sigma T_{r}}\right]+j \omega_{r} \frac{\sigma L_{s} M}{L_{r}}\right]
\end{array}\right.
$$

To get the gain matrix $K$ it is supposed that:

$$
\left\{\begin{array}{l}
K^{\prime}=K_{1}+j K_{2} \\
K^{\prime \prime}=K_{3}+j K_{4}
\end{array}\right.
$$

So,

$$
\left\{\begin{array}{l}
K_{1}=(l-1)\left(\frac{1}{\sigma T_{s}}+\frac{1}{\sigma T_{r}}\right) \\
K_{2}=-(l-1) \omega_{r} \\
K_{3}=\left(l^{2}-1\right)\left[\left(\frac{1}{\sigma T_{s}}+\frac{1}{\sigma T_{r}}\right) \frac{\sigma L_{s} M}{L_{r}}-\frac{M}{T_{r}}\right]+\frac{\sigma L_{s} M}{L_{r}}\left(\frac{1}{\sigma T_{s}}+\frac{1}{\sigma T_{r}}\right)(l-1) \\
K_{4}=-(l-1) \frac{\sigma L_{s} M}{L_{r}} \omega_{r}
\end{array}\right.
$$

According to the anti-symmetry of matrix $A$, the gain matrix $K$ is set as follows:

$K=\left[\begin{array}{cccc}K_{1} & K_{2} & K_{3} & K_{4} \\ -K_{2} & K_{1} & -K_{4} & K_{3}\end{array}\right]^{T}$

\subsection{Observer stability}

Considering the following equations:

Induction motor model: $\quad \dot{X}=A X+B U$

and

Observer model:

$$
\dot{\hat{X}}=A \hat{X}+B U+K \xi
$$

The estimated stator currents error $\left(e=I_{S}-\widehat{I}_{S}\right)$ is the deference between the observer and the induction motor models, so:

$\dot{e}=(A-K C) e$

Considering the Lyapunov function below:

$S=e^{T} e+\frac{\left(\Delta \omega_{\mathrm{r}}\right)^{2}}{\lambda}$ 
Its time derivative is:

$\frac{d S}{d t}=\left(\frac{d e^{T}}{d t}\right) e+\left(\frac{d e}{d t}\right) e^{T}+\frac{1}{\lambda} \frac{d}{d t}\left(\Delta \omega_{r}\right)^{2}$

Knowing that $\Delta \omega_{r}=0$, then:

$\frac{d S}{d t}=\left(\frac{d e^{T}}{d t}\right) e+\left(\frac{d e}{d t}\right) e^{T}$

Replacing Eq. (24) in Eq. (27) gives:

$\frac{d S}{d t}=e\left\{(A-K C)^{T}+(A-K C)\right\} e^{T}$

A sufficient condition for this estimator stability is that Eq.(28) is less than zero, and indeed, this equation is always less than zero.

\section{Simulation results}

The behavior of the proposed current sensorless vector control of an induction motor drive based on a modified adaptive observer was verified in simulation, under the MATLAB/Simulink ${ }^{\circledR}$ environment, for different operating conditions, using the motor parameters presented in Table A.1 of the Appendix.

Fig. 4 illustrates the behavior of the induction motor, under the operation of the proposed technique, from 0 to $1000 \mathrm{rpm}$ with an off-load start, and then with the introduction of the rated load torque $(5 \mathrm{Nm})$ at $t=1 \mathrm{~s}$. Figs. 4(a) and 4(b) present the estimated and measured three-phase stator currents, respectively. The three waveforms of the estimated stator currents are similar to the three waveforms of the measured stator currents. As shown in Fig. 4(c), the motor is started with a zero reference torque, and then, at $t=1 \mathrm{~s}$, the torque reference was set to 5 $\mathrm{Nm}(100 \%$ load). Fig. 4(d) plots the measured rotational speed transient response from 0 to $1000 \mathrm{rpm}$ against a $100 \%$ load torque $(5 \mathrm{Nm})$ applied at $1 \mathrm{~s}$. It can be seen that the speed control is accomplished, as planned, by applying the method without current sensors.

Decoupling is the main purpose of vector control, and this objective is fully achieved in the present case (without current sensors) as is illustrated in Fig. 4(e).

Fig. 5 presents the various quantities registered during a speed reverse test. In this context, a highperformance estimation of the three-phase stator currents was carried out by the proposed technique which is proved by the total similarity between the estimated and measured stator currents, plotted in Figs. 5(a) and 5(b), respectively. The speed reverse test has been applied at full load (5 Nm) as shown in Fig. 5(c), and low speed; as it can be seen in Fig. 5(d), the speed decreases from $200 \mathrm{rpm}$ to $-200 \mathrm{rpm}$ at $1.3 \mathrm{~s}$ and increases from $-200 \mathrm{rpm}$ to $200 \mathrm{rpm}$ at $2.6 \mathrm{~s}$. When the speed either decreases or increases, the proposed method reacts quickly and preserves the decoupling between the direct and quadrature axes, as can be seen in Fig. 5(e).

To verify the dynamics and the performance of the proposed current sensorless vector control, a variable speed test was applied. Figs. 6(a) and 6(b) present the estimated and measured phase currents, respectively. As it can be seen, there is a good match between the estimated and measured current waveforms. Fig. 6(c) illustrates the reference and the measured speed. Clearly, the motor rotation speed tracks perfectly well the reference speed. The fast dynamics and the high performance of the proposed current sensorless vector control are, therefore, confirmed.

Higher order dynamics are difficult to identify and remain excluded from the theoretical model of the system; these dynamics are generally the main cause of instability. In such linear or nonlinear systems, the presence of not modeled dynamics results in undesirable oscillations, that affect the overall stability, and leads to limited control performance. In this context, some systems need Uncertainty and Disturbance Estimator (UDE) [54,55].

In this paper, UDE is not used. In contrast, two external low-pass filters are used to filter out the highfrequency noise in the measurements of the dc-link voltage and the rotational speed, in order to reduce the sensitivity to sensor noise, instability effect due to not modeled dynamics, and the undesirable oscillations can be suppressed, thus improving the system stability.

In Figs. 7 and 8, a scenario of an experimental implementation is simulated. In the test presented in Fig. 7 , noise is injected in both dc-link voltage and speed sensors as it can be seen in Figs. 7(a) and 7(b). This noise causes ripple in the estimated stator currents, in the electromagnetic torque, as well as in the direct and quadrature stator currents, such as depicted in Figs. 7(c), 7(d) and 7(e). Fig. 7(f) presents the FFT analysis of the estimated stator current $I_{\text {sa_est }}$, where the $T H D=1.16 \%$. 
Fig. 8 presents the results saved after adding two low-pass filters to the speed and voltage measurement circuits, which reduce the noise in these measurements (see Figs. 8(a) and 8(b)). The current oscillations are suppressed (Fig. 8(c)), the ripples in torque and $(d, q)$ axes stator currents are reduced (see Fig. 8(d) and 8(e)), and more important, the THD is also decreased from $1.16 \%$ to $0.85 \%$ (Fig. 8(f)).

In the experimental implementation of the proposed method, the low-pass filters are added from the beginning, to filter out the high-frequency noise in the measurements of the dc-link voltage and the rotational speed. The equation of the low-pass filters is as follows:

$F(s)=\frac{1}{T_{f} s+1}$

Where, $T_{f}$ was chosen by trial and error method for both filters (dc-link voltage and speed), and $T_{f}=0.01$.

\section{Experimental results}

To confirm the performance and efficiency of the proposed stator-currents observer presented in the simulation model, a test bench has been developed to apply the suggested technique. The experimental test bench is shown in Fig. 9(a) and it is composed of a dSpace1104 card, a control desk software plugged into the computer, a three-phase power supply $(50 \mathrm{~Hz})$, an incremental encoder, a voltage sensor, three current sensors, a power electronics Semikron module (consisting of a rectifier and an IGBT inverter), a powder brake, and a 1.1 $\mathrm{kW}$ induction motor, whose parameters are the same used in the simulation model (see Appendix). However, it should be noted that the current sensors were not used in the control loop.

The current sensorless vector control was implemented in a DS1104 board, where ControlDesk software, measurements, and control variables can be combined. One of the board's incremental encoder interfaces picks up the encoder signal of the motor, while one Analogue/Digital Converter (ADC) is required to analyze the DCvoltage, measured by the dc-link voltage sensor. The controller board runs the control algorithm on the basis of the measured values and determines the corresponding inverter control signals, which are generated on the board's DSP subsystem through the Digital Input/Output (Digital I/O) board, to specify the converter's output voltage, and frequency (see Fig. 9(b)).

Figs 10, 11, and 12 show the experimental results of the introduced current sensorless vector control, applied to an induction motor drive operating under different conditions: $1000 \mathrm{rpm}$ at no-load and at rated load, low speed $(200 \mathrm{rpm})$ at rated load, speed reversal at full load, and variable speed (industrial benchmark test [56]). The figures show the different signals registered from the experimental tests, such as the estimated and measured stator currents, rotational speed, direct and quadrature stator currents and electromagnetic torque.

As it can be seen from Figs. 10(a) and 10(b), the estimated stator currents and the measured stator currents are coincident. These waveforms were recorded from an experimental test where the induction motor control was performed starting with a reference load torque fixed at $0 \mathrm{Nm}$. At $4.8 \mathrm{~s}$, the load torque reference raised to 5 $\mathrm{Nm}$ (rated load) in which the motor operation switched from off-load to a full load condition; the electromagnetic torque plots are given in Fig. 10(c). Figs. 10(d) and 10(e) outlining, respectively, the fast increase of the rotational speed from 0 to $1000 \mathrm{rpm}$, and the stator currents linked to the axes $(d, q)$ which are perfectly decoupled. This proves the good accuracy of the stator currents estimator.

Fig. 11 outlines the experimental results of the motor operation at low speed $(200 \mathrm{rpm})$, without current sensors, using the proposed stator current estimation technique. The estimated currents are equal to the measured ones, as shown in Figs. 11(a) and 11(b). To confirm the efficiency and the high accuracy of the control system response of the proposed current sensorless approach, the start-up of the machine was carried out under rated load, as illustrated in Fig. 11(c).

Fig. 11(d) depicts the motor reference speed and the measured rotational speed. At $3.1 \mathrm{~s}$ a speed reversal was imposed, from $200 \mathrm{rpm}$ to $-200 \mathrm{rpm}$, and back to $200 \mathrm{rpm}$ at $6.9 \mathrm{~s}$. It can be noticed that there is a very good response of the control system for the speed reversal test, even at the rated load.

As previously mentioned, to achieve a high-performance vector control it is necessary to get a perfect decoupling between the direct and quadrature quantities, which is reached in this case, and confirmed by the direct and quadrature stator currents depicted in Fig. 11(e).

The response of the control system for the industrial benchmark trajectory is shown in Fig. 12. By comparing the results displayed in Figs. 12(a) and 12(b) it can be concluded that the estimated currents are similar to the measured ones. In addition, it can be seen from Fig. 12(c) that the instantaneous speed perfectly follows the reference speed, and so, it is clear that the adopted method has a fast response despite the speed variation, with good acceleration and deceleration performance. 
The experimental tests confirm the simulation results, where the proposed current observer scheme associated with the IRFOC reveals a high precision for stator currents estimation under different operating conditions: variable speed, speed reversal, and load transients.

\section{Conclusion}

In this paper, a control strategy without current sensors, based on the indirect rotor field oriented control with a modified adaptive observer, has been presented. The vector control was proposed considering its simplicity, and wide application to different AC electrical drives. The estimation of the stator currents is proposed in order to avoid the various defects that threaten the current sensors. Consequently, the control system is simplified, which reduces costs and increases the reliability of the global system. The effectiveness and performance of the proposed current sensorless strategy have been verified by simulation and through experimental tests. Both simulation and experimental results present fast dynamics and good performance under different operating conditions, namely, load transients, speed reversal, variable speed, and low-speed operation. In conclusion, it is obvious that the proposed method of stator currents reconfiguration can be used as an effective solution in applications where current sensors failures are susceptible to occur, thus minimizing significantly the losses, and for critical applications, a temporary alternative solution which uses only mathematic calculations without additional costs, can be interesting.

\section{Acknowledgement}

This work has been achieved within the framework of CE2I project (Convertisseur d'Energie Intégré Intelligent). CE2I is co-financed by European Union with the financial support of the European Regional Development Fund (ERDF), French State and the French Region of Hauts-de-France.

As well, this work was supported by the European Regional Development Fund (ERDF) through the Operational Programme for Competitiveness and Internationalization (COMPETE 2020), under Project POCI01-0145-FEDER-029494, by National Funds through the FCT - Portuguese Foundation for Science and Technology, under Projects PTDC/EEI-EEE/29494/2017, UIDB/04131/2020, and UIDP/04131/2020.

Dedicated to the memory of Prof. Arezki MENACER, Mr. Younes AZZOUG former supervisor, who always believed in Mr. Younes AZZOUG's ability of being successful both in academic and research arenas. "You are gone but your belief in me has made this day possible" (Mr. Younes AZZOUG).

\section{References}

[1] Blaschke F. The principle of field orientation as applied to the new transvektor closed-loop control system for rotating field machines. Siemens Rev 1972;34:217-20.

[2] Tong M, Hua W, Su P, Cheng M, Meng J. Investigation of a Vector-Controlled Five-Phase Flux-Switching Permanent-Magnet Machine Drive System. IEEE Trans Magn 2016;52:1-5. doi:10.1109/TMAG.2016.2524503.

[3] Dong L, Huang Y, Jatskevich J, Liu J. Improved Fault-Tolerant Control for Brushless Permanent Magnet Motor Drives With Defective Hall Sensors. IEEE Trans Energy Convers 2016;31:789-99. doi:10.1109/TEC.2016.2526621.

[4] Biswas PC, Ghosh BC. A novel flux estimation algorithm based position sensorless field oriented vector controlled permanent magnet brushless DC motor drive. 2017 3rd Int. Conf. Electr. Inf. Commun. Technol., IEEE; 2017, p. 1-6. doi:10.1109/EICT.2017.8275231.

[5] Vagati A, Pastorelli M, Franceschini G. High-performance control of synchronous reluctance motors. IEEE Trans Ind Appl 1997;33:983-91. doi:10.1109/28.605740.

[6] Seong-Hwan Kim, Tae-Sik Park, Ji-Yoon Yoo, Gwi-Tae Park. Speed-sensorless vector control of an induction motor using neural network speed estimation. IEEE Trans Ind Electron 2001;48:609-14. doi:10.1109/41.925588.

[7] Hakan Akpolat Z, Asher GM, Clare JC. Dynamic emulation of mechanical loads using a vector-controlled induction motor-generator set. IEEE Trans Ind Electron 1999;46:370-9. doi:10.1109/41.753776.

[8] Ameid T, Menacer A, Talhaoui H, Harzelli I. Broken rotor bar fault diagnosis using fast Fourier transform applied to field-oriented control induction machine: simulation and experimental study. Int J Adv Manuf Technol 2017;92:917-28. doi:10.1007/s00170-0170143-2.

[9] Ameid T, Menacer A, Talhaoui H, Azzoug Y. Discrete wavelet transform and energy eigen value for rotor bars fault detection in variable speed field-oriented control of induction motor drive. ISA Trans 2018;79:217-31. doi:10.1016/j.isatra.2018.04.019.

[10] Azzoug Y, Menacer A, Pusca R, Romary RR, Ameid T, Amma A. Fault Tolerant Control for Speed Sensor Failure in Induction Motor Drive based on Direct Torque Control and Adaptive Stator Flux Observer. 2018 Int. Conf. Appl. Theor. Electr., IEEE; 2018 , p. 1-6. doi:10.1109/ICATE.2018.8551478.

[11] Yu Y, Chen X, Dong Z. Current sensorless direct predictive control for induction motor drives. 2017 IEEE Transp. Electrif. Conf. Expo, Asia-Pacific (ITEC Asia-Pacific), IEEE; 2017, p. 1-6. doi:10.1109/ITEC-AP.2017.8080975.

[12] Ammar A, Benakcha A, Bourek A. Adaptive MRAC-based direct torque control with SVM for sensorless induction motor using adaptive observer. Int J Adv Manuf Technol 2016. doi:10.1007/s00170-016-9840-5.

[13] Ammar A, Bourek A, Benakcha A. Sensorless SVM-Direct Torque Control for Induction Motor Drive Using Sliding Mode Observers. J Control Autom Electr Syst 2017;28:189-202. doi:10.1007/s40313-016-0294-7.

[14] Diab AAZ. Implementation of a novel full-order observer for speed sensorless vector control of induction motor drives. Electr Eng 2017;99:907-21. doi:10.1007/s00202-016-0453-7.

[15] Saleh K, Sumner M. Sensorless speed control of five-phase PMSM drives with low current distortion. Electr Eng 2018;100:357-74. doi:10.1007/s00202-017-0511-9.

[16] Bala M, Bahri I, Mercier A, Khanchoul M, Krebs G. A Speed PMSM Control Technique With a Single DC Bus current Sensor. IECON 2019 - 45th Annu. Conf. IEEE Ind. Electron. Soc., vol. 1, IEEE; 2019, p. 243-8. doi:10.1109/IECON.2019.8927460.

[17] Li S, Bai B, Chen D. Vector Control of Permanent Magnet Synchronous Motor by Using Single Current Sensor. ICPE 2019 - ECCE Asia - 10th Int. Conf. Power Electron. - ECCE Asia, 2019, p. 2556-61. 
[18] Zhao J, Nalakath S, Emadi A. A High Frequency Injection Technique With Modified Current Reconstruction for Low-Speed Sensorless Control of IPMSMs With a Single DC-Link Current Sensor. IEEE Access 2019;7:136137-47. doi:10.1109/ACCESS.2019.2942148.

[19] Zhao J, Nalakath S, Emadi A. Observer Assisted Current Reconstruction Method with Single DC-Link Current Sensor for Sensorless Control of Interior Permanent Magnet Synchronous Machines. IECON 2019 - 45th Annu. Conf. IEEE Ind. Electron. Soc., IEEE; 2019, p. 1228-33. doi:10.1109/IECON.2019.8926822.

[20] Wang W, Yan H, Xu Y, Zou J, Zhang X, Zhao W, et al. New Three-Phase Current Reconstruction for PMSM Drive with Hybrid Space Vector Pulse Width Modulation Technique. IEEE Trans Power Electron 2020;8993:1-1. doi:10.1109/TPEL.2020.2997986.

[21] Aminoroaya I, Vaez-Zadeh S. Permanent magnet synchronous motor control using DC-Link current regulation. IECON 2016 - 42nd Annu. Conf. IEEE Ind. Electron. Soc., IEEE; 2016, p. 7077-82. doi:10.1109/IECON.2016.7793899.

[22] Li Z, Guo Y, Xia J, Li H, Zhang X. Variable Sampling Frequency Model Predictive Torque Control for VSI-Fed IM Drives Without Current Sensors. IEEE J Emerg Sel Top Power Electron 2020;6777:1-1. doi:10.1109/JESTPE.2020.2968387.

[23] Wu C, Jiao Y, Nian H, Blaabjerg F. A Simplified Stator Frequency and Power Control Method of DFIG-DC System Without Stator Voltage and Current Sensors. IEEE Trans Power Electron 2020;35:5562-6. doi:10.1109/TPEL.2019.2953677.

[24] Zhemin Hu; Ming Yang; Kaixuan Yang; Dianguo Xu. Current Sensorless Direct Predictive Control for Permanent-Magnet Synchronous Motor Drives. PCIM Asia 2016; Int. Exhib. Conf. Power Electron. Intell. Motion, Renew. Energy Energy Manag. Proc., IEEE; 2016, p. 1-8.

[25] Rafa S, Larabi A, Barazane L, Manceur M, Essounbouli N, Hamzaoui A. Implementation of a new fuzzy vector control of induction motor. ISA Trans 2014;53:744-54. doi:10.1016/j.isatra.2014.02.005.

[26] Joo, Myung-Joong Youn, Hwi-Beom Shi H-G. Estimation of Phase Currents from a DC-Link Current Sensor Using Space Vector PWM Method. Electr Mach Power Syst 2000;28:1053-69. doi:10.1080/073135600449107.

[27] Chunpeng Zhang, Fei Lin. A single current sensor control technique for induction motors. Proceedings. Int. Conf. Power Syst. Technol., vol. 4, IEEE; 2002, p. 2290-3. doi:10.1109/ICPST.2002.1047192.

[28] Metidji B, Taib N, Baghli L, Rekioua T, Bacha S. Low-Cost Direct Torque Control Algorithm for Induction Motor Without AC Phase Current Sensors. IEEE Trans Power Electron 2012;27:4132-9. doi:10.1109/TPEL.2012.2190101.

[29] Noordeen S, Karthikeyan K, Parveen M a N. Direct Torque Control for Induction Motor Without Current Sensors. Int J Eng Res Technol 2013;2:388-97.

[30] Corne A, Martin J-P, Nahid-Mobarakeh B, Pierfederici S. Current sensorless control using a nonlinear observer applied to a wound rotor synchronous machine. 2017 IEEE Transp. Electrif. Conf. Expo, IEEE; 2017, p. 436-41. doi:10.1109/ITEC.2017.7993310.

[31] Li Y, Yang M, Long J, Liu Z, Xu D. Current sensorless predictive control based on extended kalman filter for pmsm drives. 2017 IEEE Transp Electrif Conf Expo, Asia-Pacific, ITEC Asia-Pacific 2017 2017. doi:10.1109/ITEC-AP.2017.8080902.

[32] Woo-Cheol Lee, Taeck-Kie Lee, Dong-Seok Hyun. Comparison of single-sensor current control in the DC link for three-phase voltage-source PWM converters. IEEE Trans Ind Electron 2001;48:491-505. doi:10.1109/41.925576.

[33] Barba G, Glielmo L, Perna V, Vasca F. Current sensorless induction motor observer and control for hybrid electric vehicles. 2001 IEEE 32nd Annu. Power Electron. Spec. Conf. (IEEE Cat. No.01CH37230), vol. 2, IEEE; 2001 , p. 1224-9. doi:10.1109/PESC.2001.954286.

[34] Yongchang Zhang, Zhengming Zhao, Ting Lu, Liqiang Yuan, Wei Xu, Jianguo Zhu. A comparative study of Luenberger observer, sliding mode observer and extended Kalman filter for sensorless vector control of induction motor drives. 2009 IEEE Energy Convers. Congr. Expo., IEEE; 2009, p. 2466-73. doi:10.1109/ECCE.2009.5316508

[35] Blaabjerg F. An ideal PWM-VSI inverter using only one current sensor in the DC-link. Proc. 5th Int. Conf. Power Electron. Var. Drives, vol. 1994, IEE; 1994, p. 458-64. doi:10.1049/cp:19941009.

[36] Boys JT. Novel current sensor for PWM AC drives. IEE Proc B Electr Power Appl 1988;135:27. doi:10.1049/ip-b.1988.0005

[37] Petruzziello F, Joos G, Ziogas PD. Some implementation aspects of line current reconstruction in three phase PWM inverters. [Proceedings] IECON '90 16th Annu. Conf. IEEE Ind. Electron. Soc., IEEE; n.d., p. 1149-54. doi:10.1109/IECON.1990.149299.

[38] Yu Y, Wang Z, Xu D, Zhou T, Xu R. Speed and Current Sensor Fault Detection and Isolation Based on Adaptive Observers for IM Drives. J Power Electron 2014;14:967-79. doi:10.6113/JPE.2014.14.5.967.

[39] Grouz F, Sbita L, Boussak M. Current sensors faults detection, isolation and control reconfiguration for PMSM drives. 2013 Int. Conf. Electr. Eng. Softw. Appl., IEEE; 2013, p. 1-6. doi:10.1109/ICEESA.2013.6578414.

[40] Karimi S, Gaillard A, Poure P, Saadate S. Current Sensor Fault-Tolerant Control for WECS With DFIG. IEEE Trans Ind Electron 2009;56:4660-70. doi:10.1109/TIE.2009.2031193.

[41] Dybkowski M, Klimkowski K. Stator current sensor fault detection and isolation for vector controlled induction motor drive. 2016 IEEE Int. Power Electron. Motion Control Conf., IEEE; 2016, p. 1097-102. doi:10.1109/EPEPEMC.2016.7752147.

[42] Rothenhagen K, Fuchs FW. Doubly Fed Induction Generator Model-Based Sensor Fault Detection and Control Loop Reconfiguration. IEEE Trans Ind Electron 2009;56:4229-38. doi:10.1109/TIE.2009.2013683.

[43] Rothenhagen K, Fuchs FW. Current Sensor Fault Detection, Isolation, and Reconfiguration for Doubly Fed Induction Generators. IEEE Trans Ind Electron 2009;56:4239-45. doi:10.1109/TIE.2009.2017562.

[44] Chakraborty C, Verma V. Speed and Current Sensor Fault Detection and Isolation Technique for Induction Motor Drive Using Axes Transformation. IEEE Trans Ind Electron 2015;62:1943-54. doi:10.1109/TIE.2014.2345337.

[45] Manohar M, Das S, Kumar R. A robust current sensor fault detection scheme for sensorless induction motor drive. 2017 IEEE PES Asia-Pacific Power Energy Eng. Conf., IEEE; 2017, p. 1-6. doi:10.1109/APPEEC.2017.8308967.

[46] Manohar M, Das S. Current Sensor Fault-Tolerant Control for Direct Torque Control of Induction Motor Drive Using Flux-Linkage Observer. IEEE Trans Ind Informatics 2017;13:2824-33. doi:10.1109/TII.2017.2714675.

[47] Yu Y, Zhao Y, Wang B, Huang X, Xu D. Current Sensor Fault Diagnosis and Tolerant Control for VSI-Based Induction Motor Drives. IEEE Trans Power Electron 2018;33:4238-48. doi:10.1109/TPEL.2017.2713482.

[48] Luenberger D. An introduction to observers. IEEE Trans Automat Contr 1971;16:596-602. doi:10.1109/TAC.1971.1099826

[49] KAUTSKY J, NICHOLS NK, VAN DOOREN P. Robust pole assignment in linear state feedback. Int J Control 1985;41:1129-55. doi:10.1080/0020718508961188.

[50] KELLER H. Non-linear observer design by transformation into a generalized observer canonical form. Int J Control 1987;46:1915-30. doi:10.1080/00207178708934024

[51] Yih-Guang Leu, Tsu-Tian Lee, Wei-Yen Wang. Observer-based adaptive fuzzy-neural control for unknown nonlinear dynamical systems. IEEE Trans Syst Man Cybern Part B 1999;29:583-91. doi:10.1109/3477.790441.

[52] Kubota H, Sato I, Tamura Y, Matsuse K, Ohta H, Hori Y. Regenerating-mode low-speed operation of sensorless induction motor drive with adaptive observer. IEEE Trans Ind Appl 2002;38:1081-6. doi:10.1109/TIA.2002.800575.

[53] Miklosovic R, Radke A, Zhiqiang Gao. Discrete implementation and generalization of the extended state observer. 2006 Am. Control Conf., IEEE; 2006, p. 6 pp. doi:10.1109/ACC.2006.1656547.

[54] Gökçek C, Davison DE, Kabamba PT, Meerkov SM. Robustness of control systems with respect to disturbance model uncertainty. IFAC Proc Vol 1999;32:3484-9. doi:10.1016/S1474-6670(17)56595-7. 
[55] Stobart RK, Kuperman A, Zhong Q-C. Uncertainty and Disturbance Estimator-Based Control for Uncertain LTI-SISO Systems With State Delays. J Dyn Syst Meas Control 2011;133:024502. doi:10.1115/1.4003265.

[56] Glumineau A, de León Morales J. Sensorless AC Electric Motor Control. Cham: Springer International Publishing; 2015. doi:10.1007/978-3-319-14586-0.

\section{Figures}

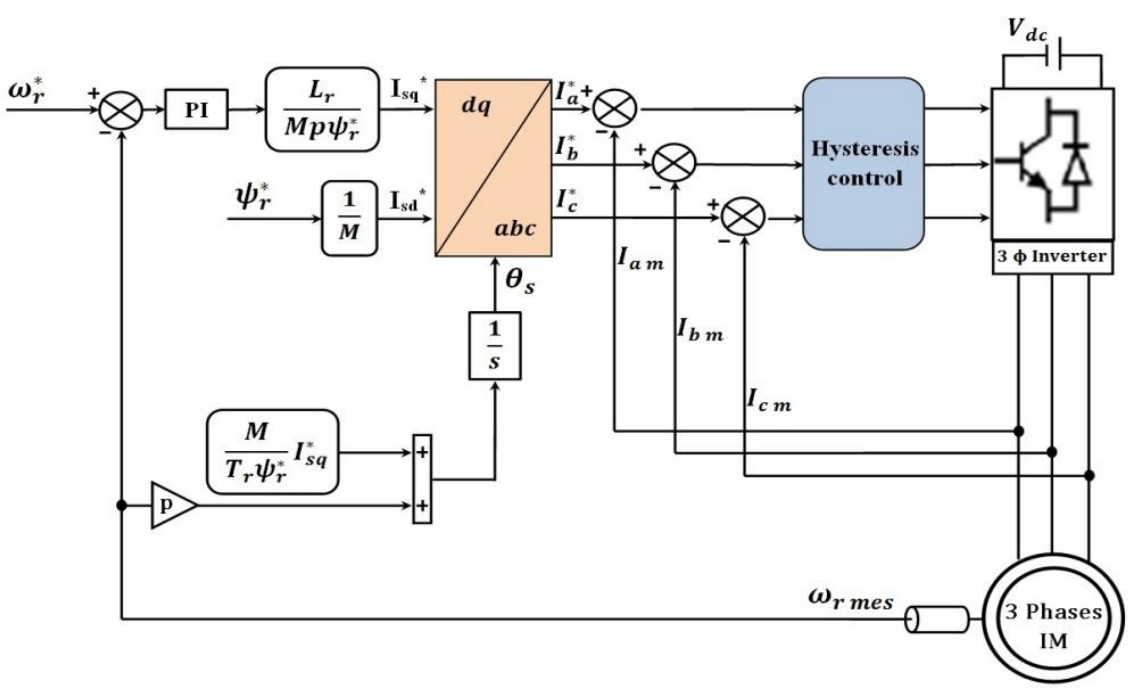

Fig. 1 Basic indirect field oriented control scheme.

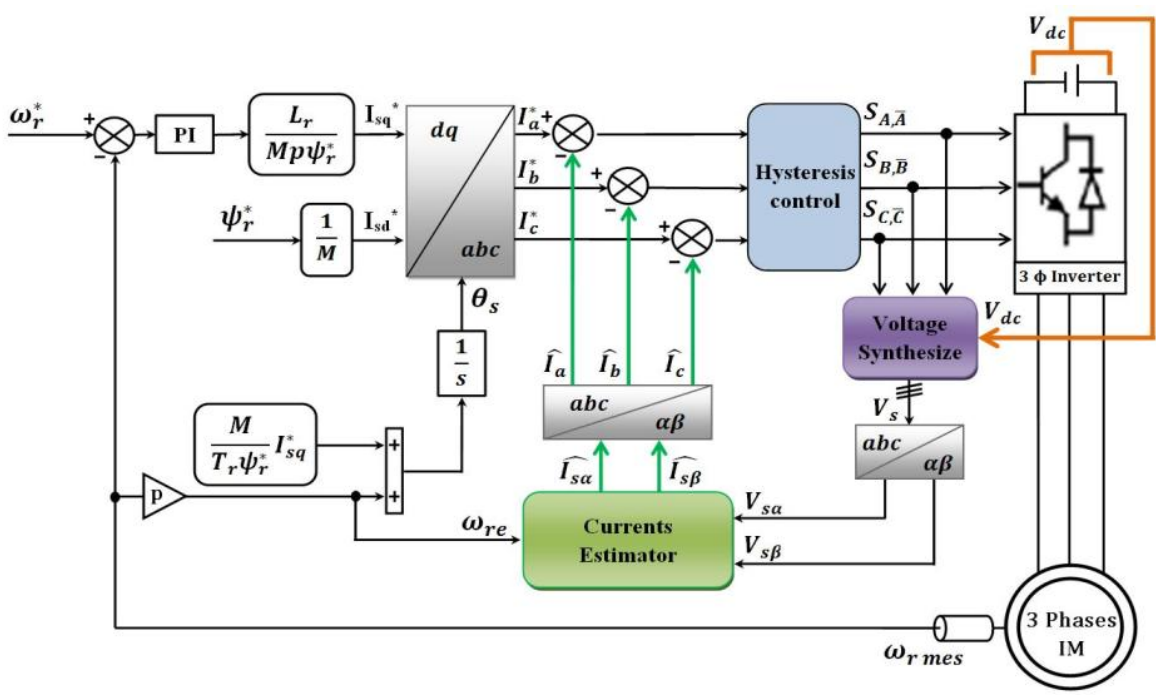

Fig. 2 Proposed current sensorless IRFOC scheme.

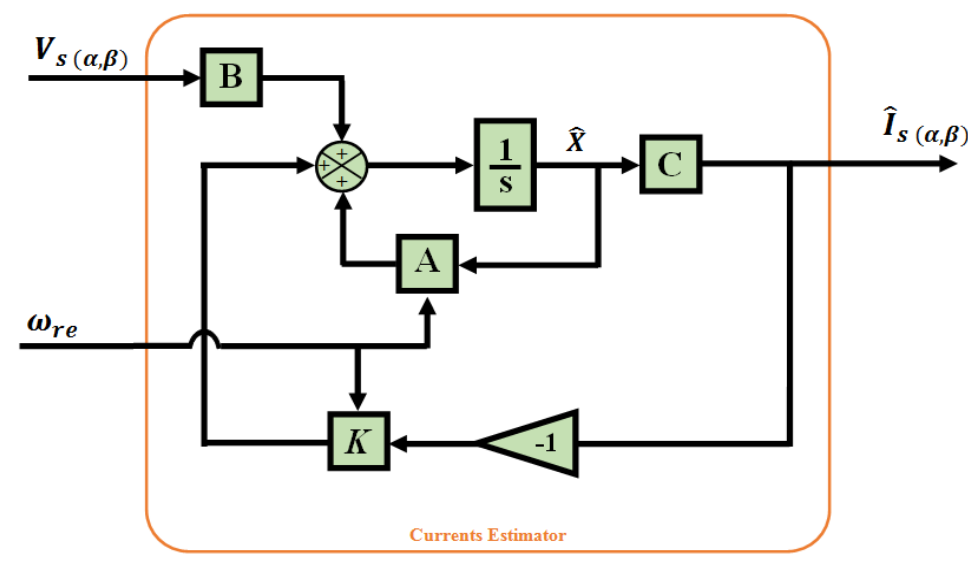

Fig. 3 Proposed current observer scheme. 
(a)
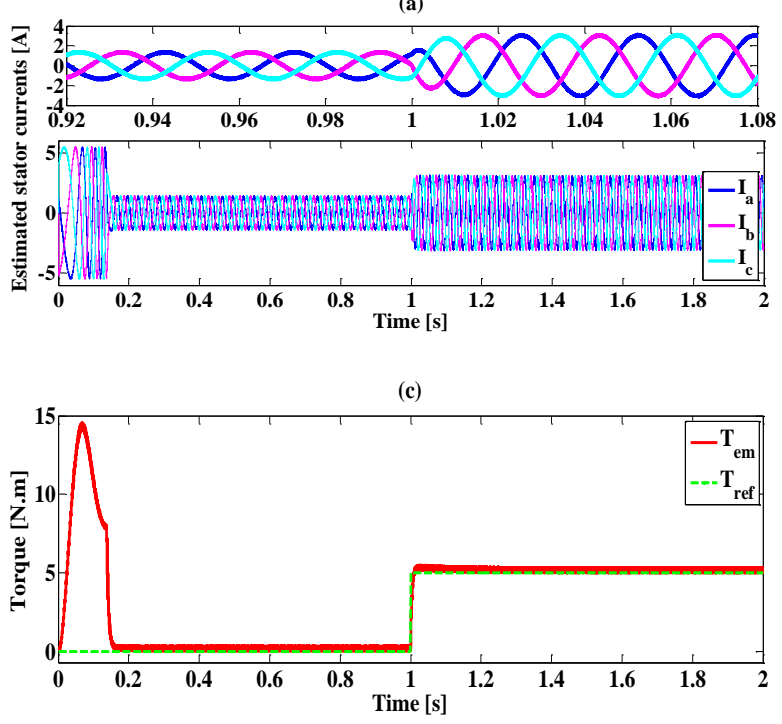

(b)

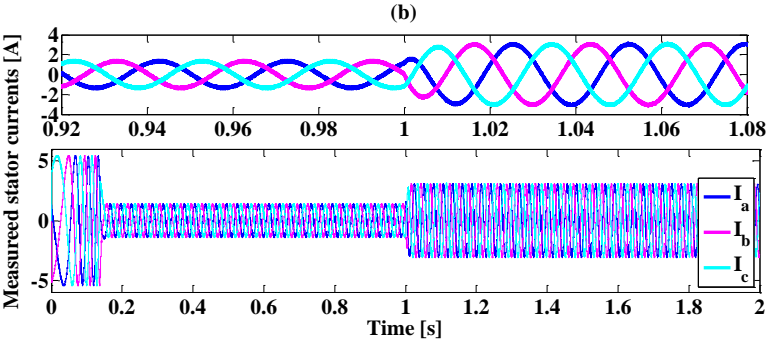

(d)

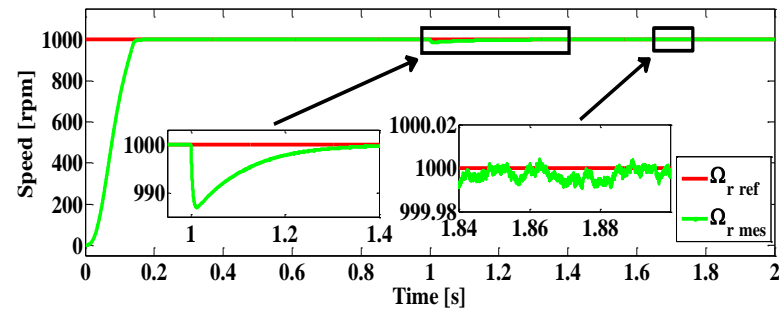

(e)

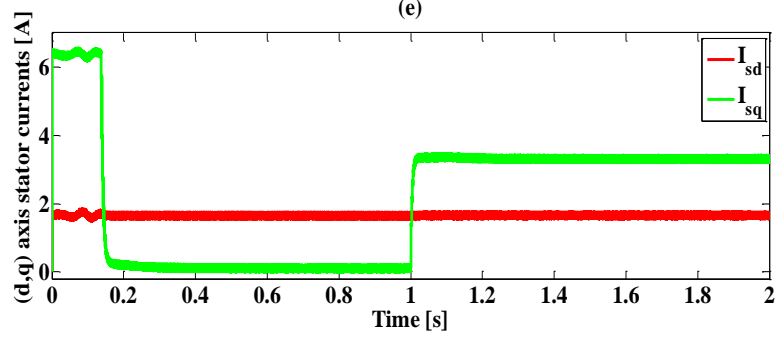

Fig. 4 Simulation results of the system response from 0 to $1000 \mathrm{rpm}$ : (a) estimated stator currents, (b) measured stator currents, (c) electromagnetic torque, (d) reference and measured speed, (e) direct and quadrature currents.
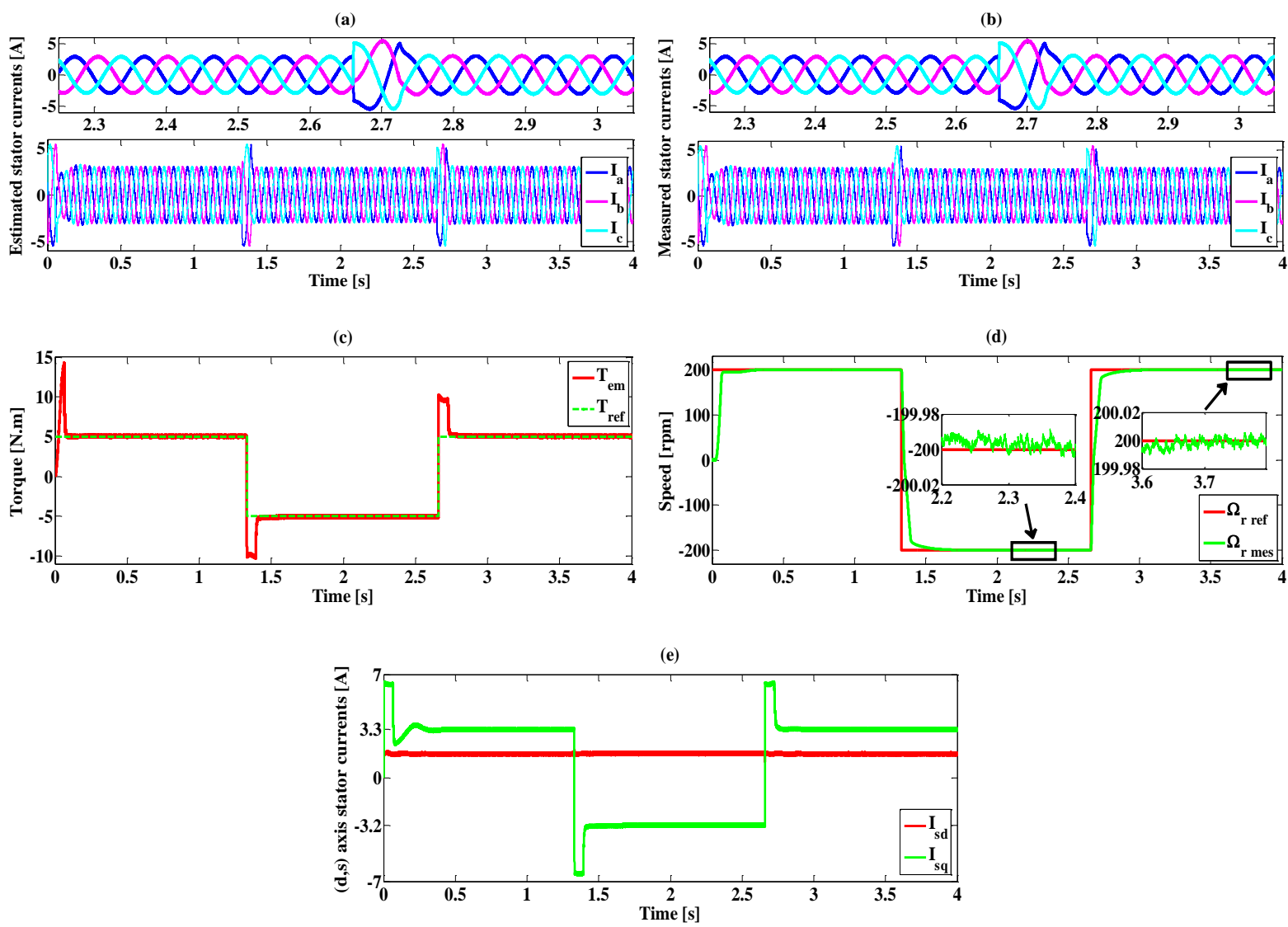

Fig. 5 Simulation results of the system response under speed reverse at low speed ( $\pm 200 \mathrm{rpm})$ and full load: (a) estimated stator currents, (b) measured stator currents, (c) electromagnetic torque, (d) reference and measured speed, (e) direct and quadrature currents. 

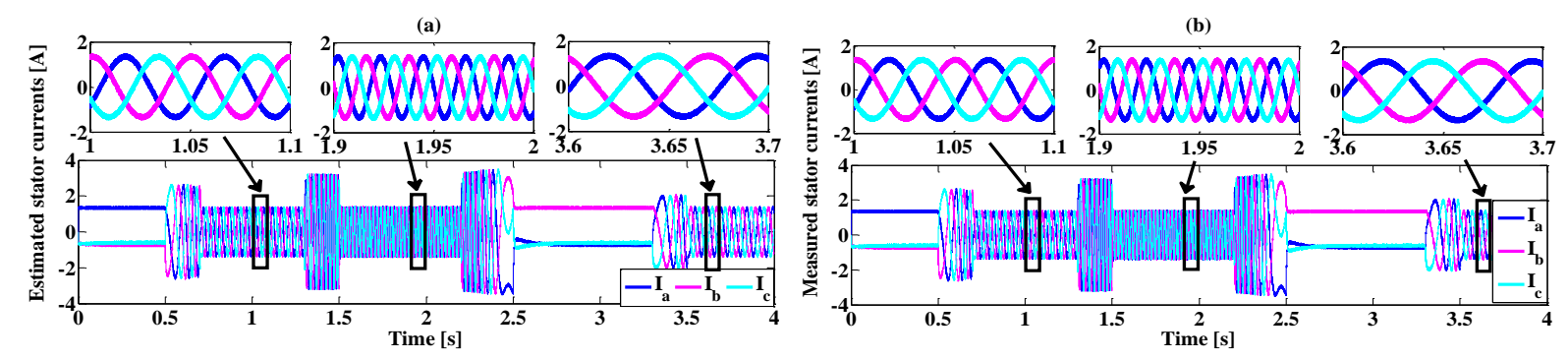

(c)

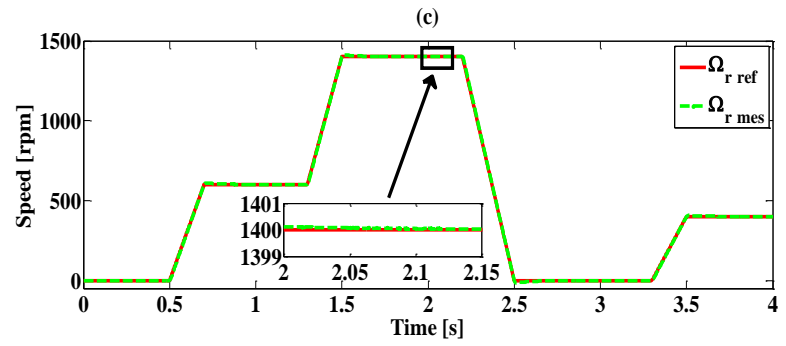

Fig. 6 Simulation results of the variable speed test (industrial benchmark test): (a) estimated stator currents, (b) measured stator currents, (c) reference and measured speed. 
(a)

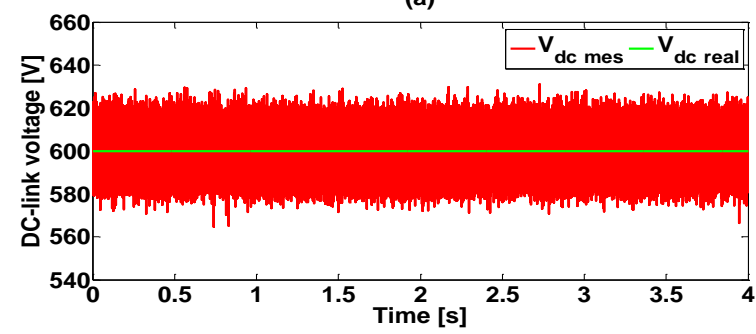

(b)

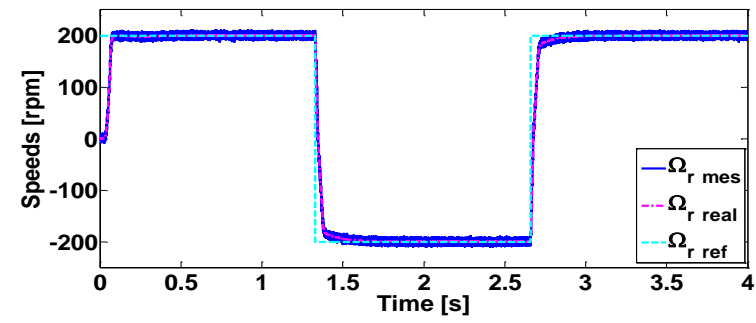

(c)

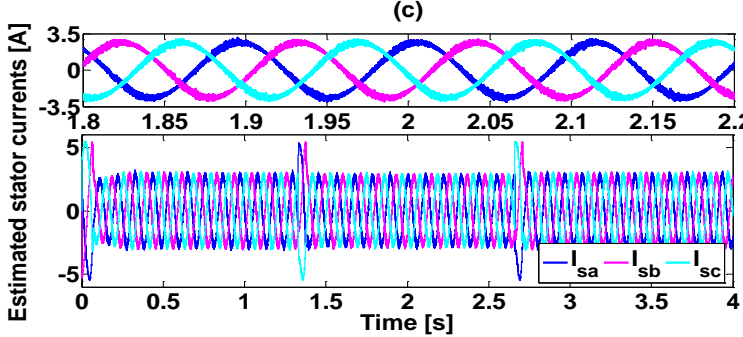

(d)

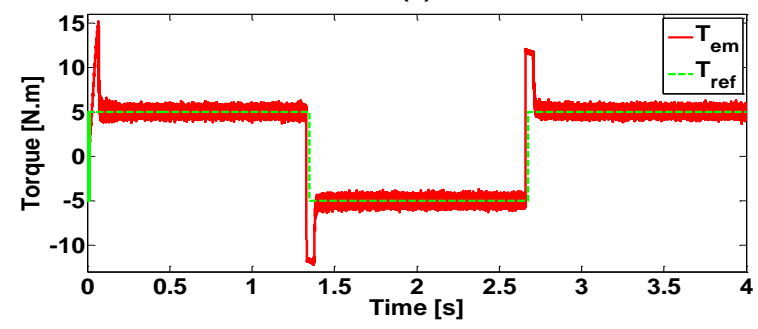

(e)

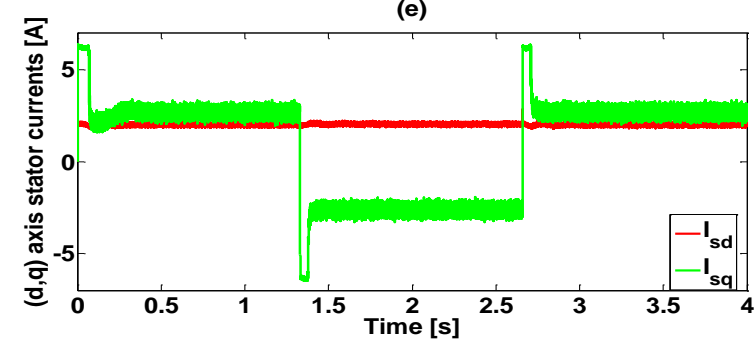

(f)

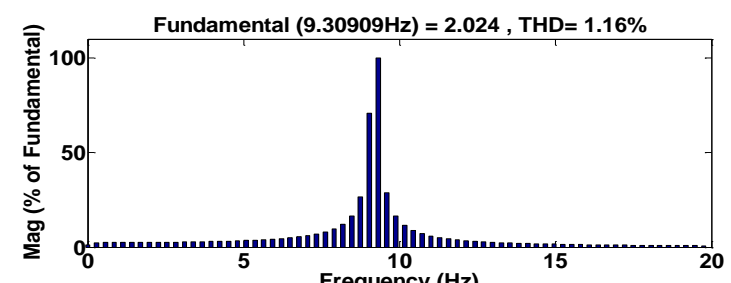

Fig. 7 Simulation results with noise in both speed and dc-link sensors: (a) dc-link voltage, (b) reference, real and measured speeds, (c) estimated stator currents, (d) electromagnetic torque, (e) direct and quadrature currents and (f) FFT analysis of $I_{s a}$ stator current. (a)

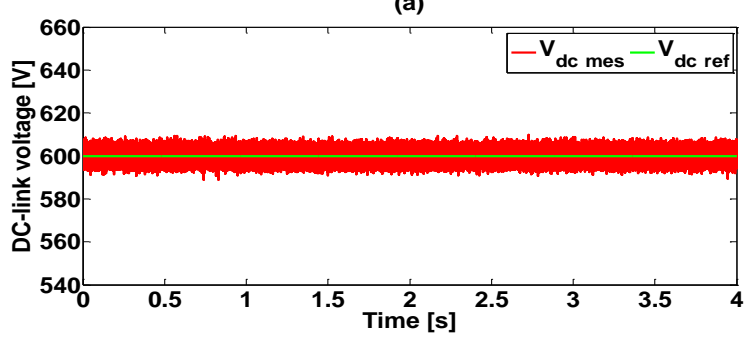

(b)

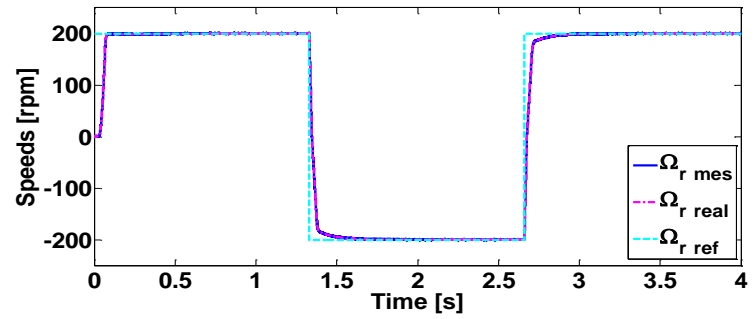

(c)

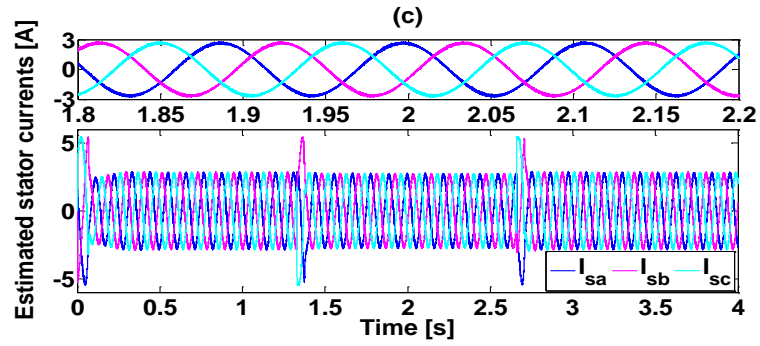

(d)

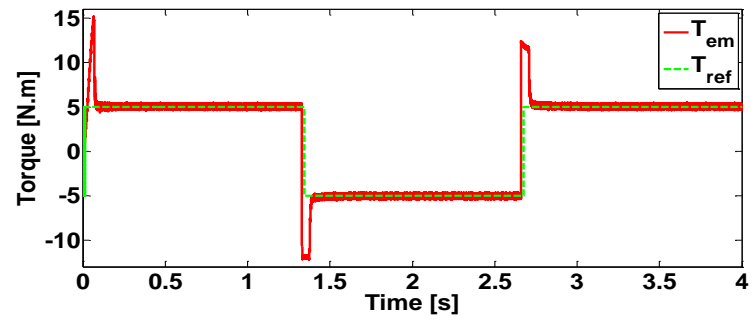

(e)

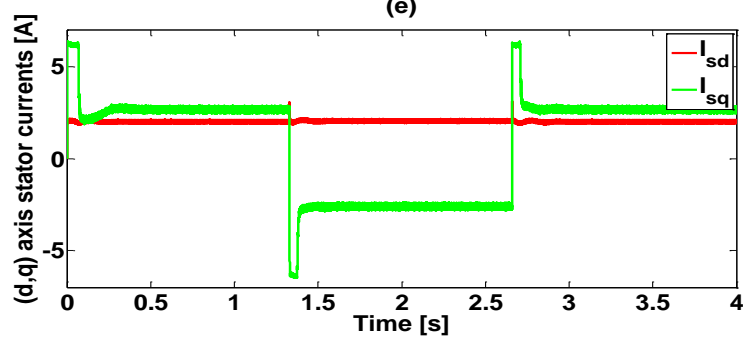

(f)

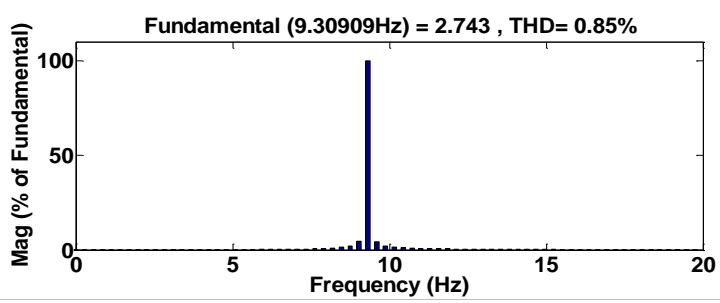

Fig. 8 Simulation results with low-pass filter in both speed and dclink sensors: (a) dc-link voltage, (b) reference, real and measured speeds, (c) estimated stator currents, (d) electromagnetic torque, (e) direct and quadrature currents and (f) FFT analysis of $I_{s a}$ stator current. 
(a)

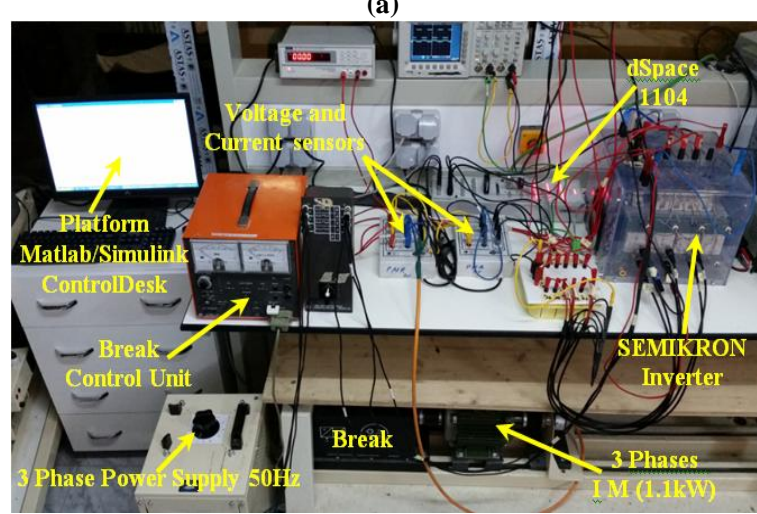

(b)

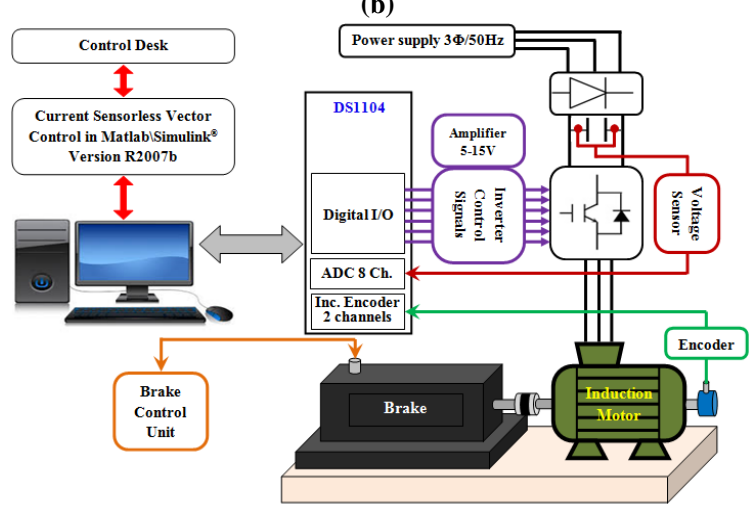

Fig. 9 Experimental implementation: (a) laboratory experimental test bench, (b) descriptive diagram of the experimental implementation.
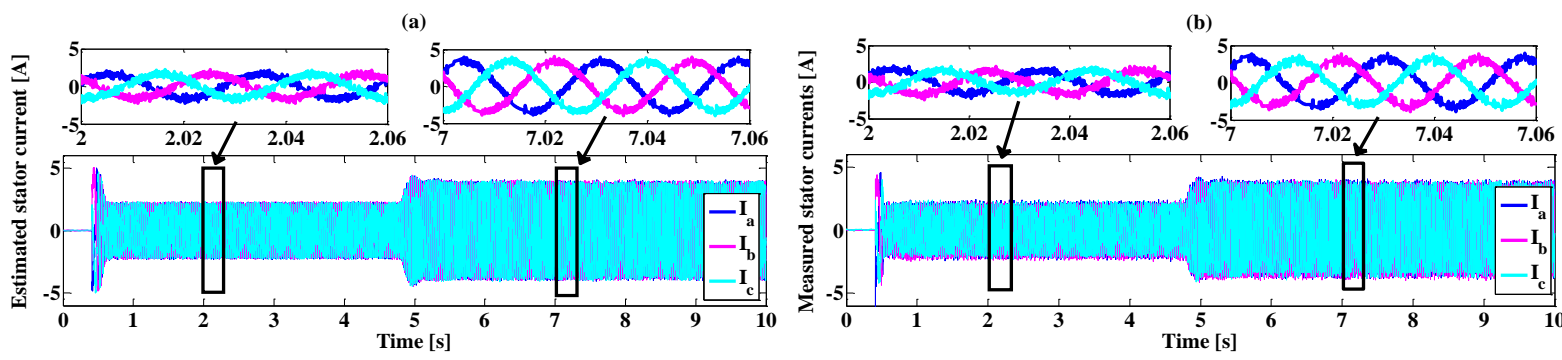

(c)
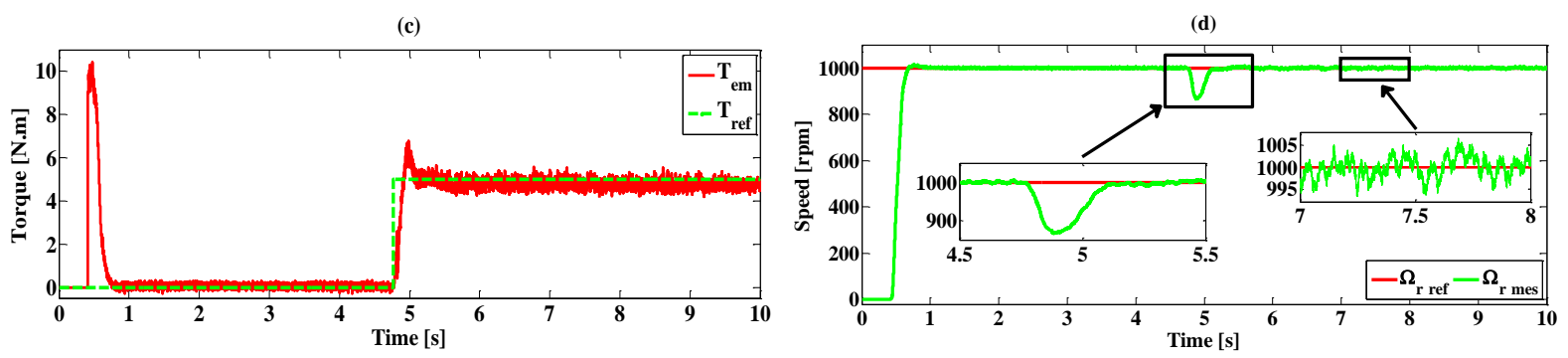

(e)

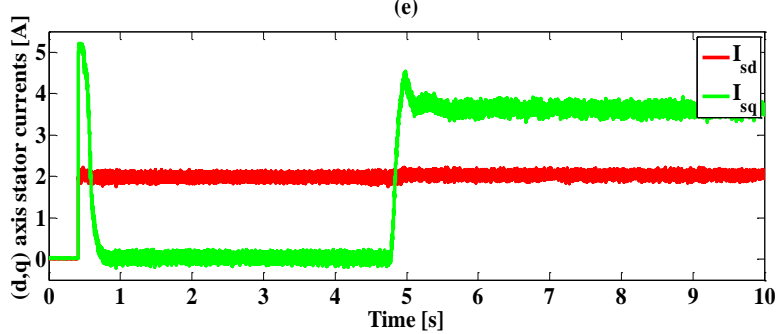

Fig. 10 Experimental results of the system response from 0 to $1000 \mathrm{rpm}$ : (a) estimated stator currents, (b) measured stator currents, (c) electromagnetic torque, (d) reference and measured speed, (e) direct and quadrature currents. 

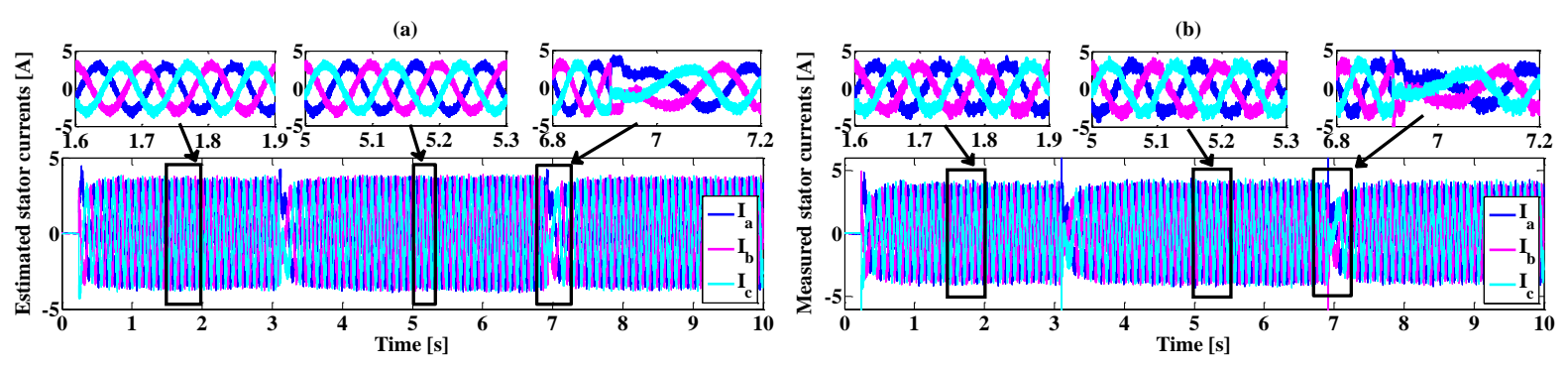

(c)
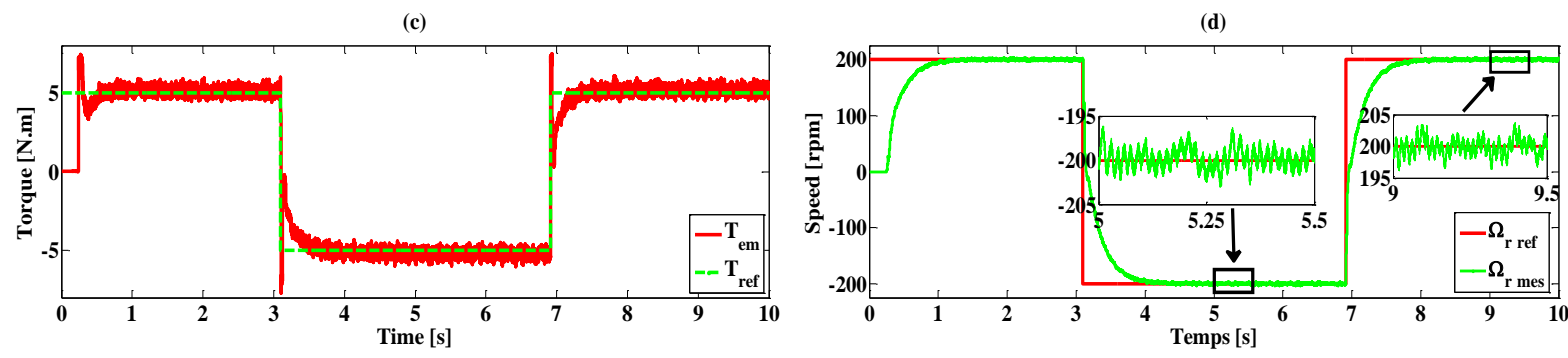

(e)

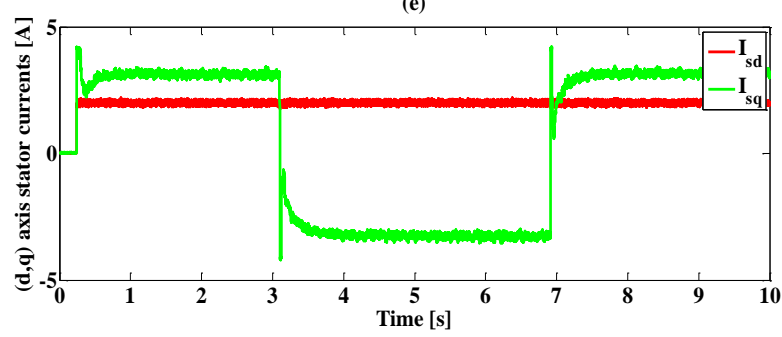

Fig. 11 Experimental results of system response under speed reverse at low speed ( $\pm 200 \mathrm{rpm})$ : (a) estimated stator currents, (b) measured stator currents, (c) electromagnetic torque, (d) reference and measured speed, (e) direct and quadrature currents.
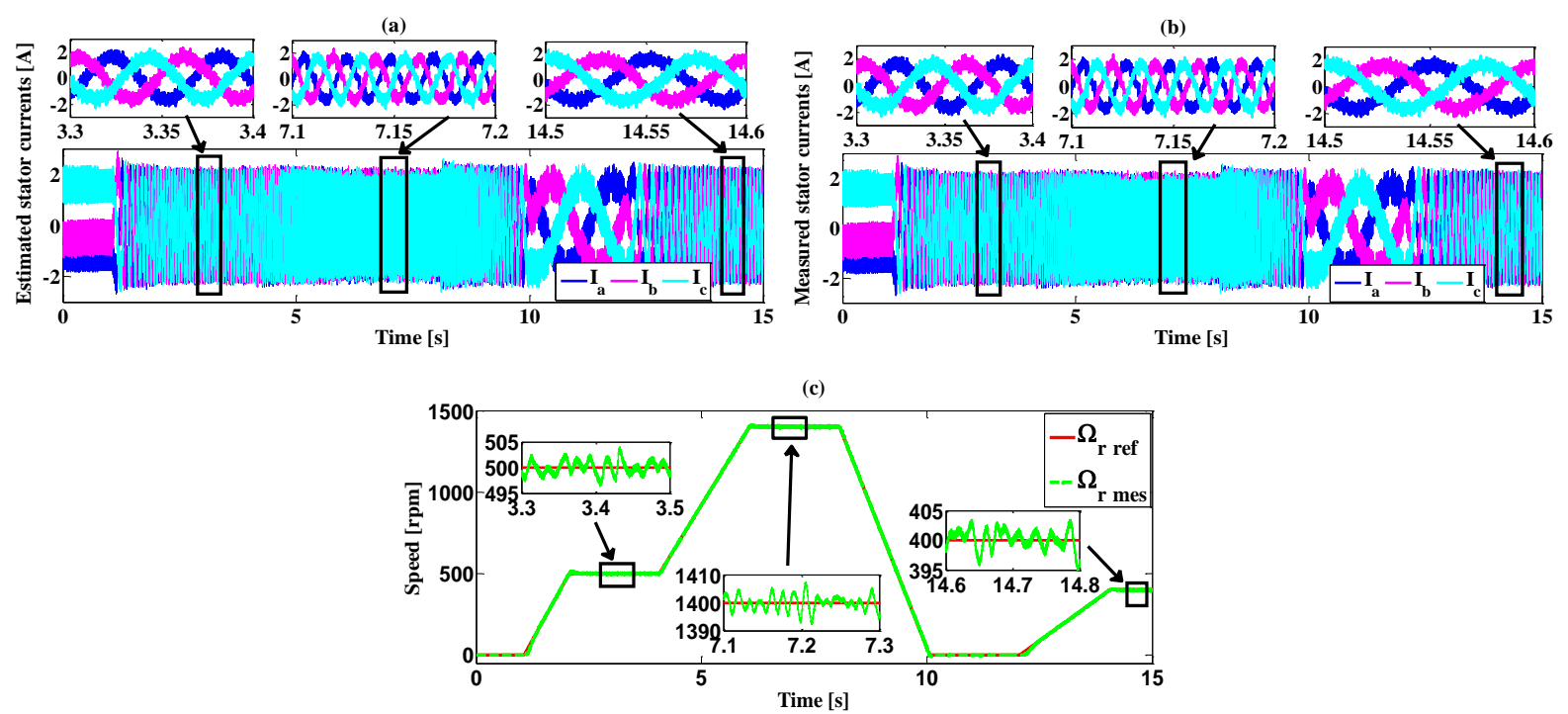

Fig. 12 Experimental results for the industrial benchmark test: (a) estimated stator currents, (b) measured stator currents, (c) reference and measured speed. 


\section{Appendix A}

Table A.1 Specifications and parameters of the induction motor used in simulation and experimental tests.

\begin{tabular}{|l|l|l|l|}
\hline \multicolumn{2}{|c|}{ Specifications } & \multicolumn{2}{c|}{ Parameters } \\
\hline Nominal power $[\mathrm{kW}]$ & 1.1 & $\mathrm{R}_{\mathrm{s}}[\Omega]$ & 6.75 \\
\hline Nominal voltage $[\mathrm{V}]$ & 400 & $\mathrm{R}_{\mathrm{r}}[\Omega]$ & 6.21 \\
\hline Nominal current $[\mathrm{A}]$ & 2.5 & $\mathrm{~L}_{\mathrm{s}}[\mathrm{H}]$ & 0.5192 \\
\hline Frequency $[\mathrm{Hz}]$ & 50 & $\mathrm{~L}_{\mathrm{r}}[\mathrm{H}]$ & 0.5192 \\
\hline Number of pole pairs & 2 & $\mathrm{M}[\mathrm{H}]$ & 0.4957 \\
\hline Nominal speed [rpm] & 1450 & $\mathrm{~J}\left[\mathrm{Kg} \cdot \mathrm{m}^{2}\right]$ & 0.0124 \\
\hline & & $\mathrm{f}\left[\mathrm{Nm} . \mathrm{rad}^{-1}\right]$ & 0.002 \\
\hline
\end{tabular}

Table A.2 PI regulator values used in simulation and experimental tests.

\begin{tabular}{|c|c|c|c|}
\hline \multicolumn{2}{|c|}{ Simulation } & \multicolumn{2}{c|}{ Experimental implementation } \\
\hline$K p_{\omega}=0.329$ & $K i_{\omega}=2.8$ & $K p_{\omega}=0.02$ & $K i_{\omega}=0.674$ \\
\hline \multicolumn{2}{|c|}{$l=1.001$} & \multicolumn{2}{|c|}{$l=1.004$} \\
\hline
\end{tabular}

\section{Nomenclature}

$\mathrm{IM}$

Induction Motor

$\mathrm{AC}$

Alternative Current

DC

Direct Current

PMSM

Permanent Magnet Synchronous Motor

PWM

Pulse Width Modulation

VSI

Voltage Source Inverter

$\mathrm{VC}$

Vector Control

IRFOC

Indirect Rotor Field Oriented Control

FTC

Fault-Tolerant Control

FDI

Fault Detection and Isolation

UDE

Uncertainty and Disturbance Estimator

$V_{d c}$

DC-link voltage

$V_{s}$

Three phases stator voltages

$I_{a}, I_{b}, I_{c}$

$(a, b, c)$ axis stator currents

$V_{s d}, V_{s q}$

$(d, q)$ axis stator voltages

$I_{s d}, I_{s q}$

$(d, q)$ axis stator currents

$\varphi_{r d}, \varphi_{r q}$

$(d, q)$ axis rotor fluxes

$V_{s \alpha}, V_{s \beta}$

$(\alpha, \beta)$ axis stator voltages

$I_{s \alpha}, I_{s \beta}$

$(\alpha, \beta)$ axis stator currents

$\varphi_{r \alpha}, \varphi_{r \beta}$

$(\alpha, \beta)$ axis rotor fluxes

$\varphi_{r}$

Rotor flux magnitude

$\omega_{s}$

Synchronous speed

$\omega_{r}$

Rotor angular speed

$\omega_{e}$

Electrical angular speed

$\Omega_{r}$

Mechanical speed

$T_{e}, T_{l}$

Electromagnetic and load torques 